\title{
Simulation of Hydraulic System with AMESim for Aerodynamic Brake of High- speed Train
}

\author{
ZhuoJun Luo ${ }^{1}$, Jianyong Zuo ${ }^{1 *}$, Liguo Zhang ${ }^{2}$ \\ 1. Railway and Urban Rail Traffic Academy, Tongji University, Shanghai, 200092 China. \\ 2. Technology Center, CSR Qingdao Sifang Locomotive and Rolling Stock Co. ,Ltd. Qingdao, 266031 China. \\ *e-mail: zuojy66@163.com
}

\begin{abstract}
This paper uses AMESim software to model the hydraulic system in the aerodynamic brake system. First we will have a brief introduction about the hydraulic system to be simulated. Than the hydraulic system is modeled and simulated, the results of the simulations are analyzed.
\end{abstract}

Keywords- hydraulic system, AMESim, aerodynamic brake, simulation.

\section{INTRODUCTION}

In an aerodynamic brake system [1], it is the brake panel who acts on the wind when the train is running to produce a force whose direction is opposite to that of the train's. Since hydraulic systems have many advantages, the brake panel is drove by a hydraulic system. The main advantages of hydraulic systems [2] include: relatively light weight per unit power, flexible and convenient layout, smooth working and quick response, easy to be automated and so on.

Instead of using an electric motor, the hydraulic system described in this paper uses compressed air in the train pipe as power source, and a pressurized cylinder [3] is used to produce high pressure oil.

This article uses the AMESim software [4] to model the hydraulic system of the aerodynamic brake system. Then the simulation results are analyzed to judge the performance of the given hydraulic system.

\section{SYSTEM DISCRIPTION AND MODELING}

\section{A. Skematic Diagram of the Hydraulic System}

The schematic diagram of hydraulic system is shown in Figure 1. It consists of two parts. Part I is a power source part, it is input with compressed air and then the compressed air drives the piston of the pressurized cylinder, which pumps oil from the tank and supplies high pressure oil as output. Part II is a function part, it regulates the high pressure oil and drives two cylinders, which drives the brake panel.

In part I, the pressure reducing valve is used to keep the pressure of compressed air input into the system stable. The pressurized cylinder unit consists of a pressurized cylinder and some auxiliary components, and it can realize the reciprocating motion of the pressurized cylinder piston. If the piston of the pressurized cylinder moves towards right at first, when it comes to the end of its stroke, the pressurized cylinder unit will output a compressed air signal. Then with the pressure of the compressed air signal exerting on the right side of the pneumatic operated directional valve, it will change its position, thus the flow direction of compressed air will change too. As a result of the changed flow direction of compressed air, the piston of the pressurized cylinder will move towards left. Thus the piston moves back and forward and supplies high pressure oil continuously until the pressure of the hydraulic accumulator rises up to about $20 \mathrm{MPa}$ and the forces of both sides of the piston attain equilibrium.

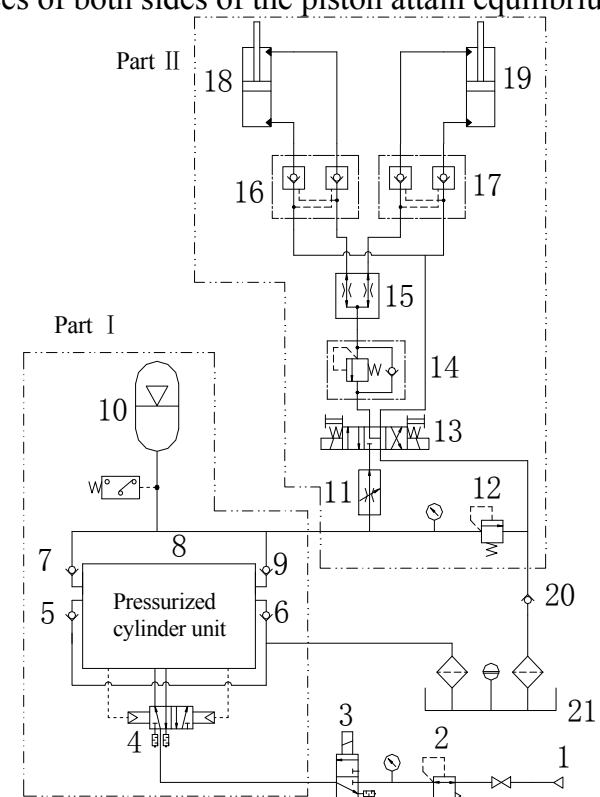

1:Compressed air input 2:Pressure reducing valve 3,13:Solenoid directional valve 4: pneumatic operated directional valve $5,6,7,9,20$ :hydraulic check valve 8:Pressurized cylinder unit 10:Hydraulic accumulator 11:Speed control valve 12:Pressure relief valve 14:Counter balance valve 15:Flow divider valve 16,17:Hydraulic lock 18,19:Hydraulic cylinder 21:Tank

Figure 1. Skematic diagram of the hydraulic system

In part II, the function of the speed control valve is to make the output flow rate of this valve stable, thus the speed of the hydraulic cylinder will be stable. The counter balance valve is used to produce back pressure to counter the load, which pulls the piston towards outside, when the piston of the hydraulic cylinder stretches out. The flow divider valve is used to synchronize the movement of the two hydraulic cylinders. 


\section{B. Component Modeling}

Because some components of the hydraulic system are not included in the AMESim software's component library, some of the components must be built by users. These components include pneumatic operated directional valve, pressurized cylinder and flow divider valve. They can be built using the "pneumatic component design" and the "hydraulic component design" libraries of the AMESim software.

The AMESim model of pneumatic operated directional valve is show in Figure 2. The ports named "pneumatic pilot" are the ports where the compressed air signal inputs. Figure 3 shows the model of flower divider valve, the flow rates of port "output 1" and "output 2" are the same and this result to the synchronization of the two hydraulic cylinders.

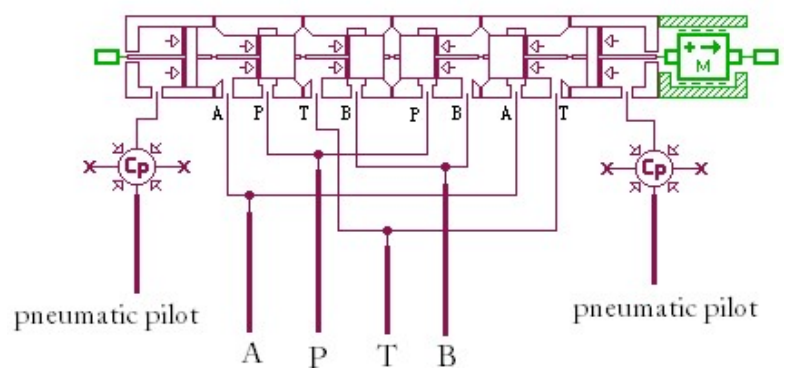

Figure 2. AMESim model of pneumatic operated directional valve

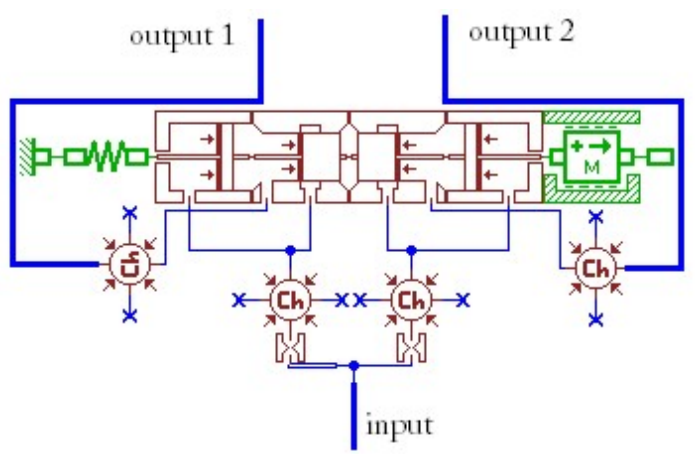

Figure 3. AMESim model of flow divider valve

\section{Simulation And Result AnAlysis}

Since the hydraulic system to be simulated is complicated, it has been divided into two parts in order to save simulation time. One part is the power source part mentioned above, and the other is the function part.

\section{A. Simulation and result analysis of the power source part}

By using the models built above and the models in the "pneumatic" and "hydraulic" libraries of the AMESim software, we can build the model of the power source part. Figure 4 shows the AMESim model of the power source part.

Before simulation, the main parameters are set as follow: pressure of the pneumatic ideal pressure source is set 8 bar; the diameter of the pressurized cylinder at the air chamber is $160 \mathrm{~mm}$; the diameter of the pressurized cylinder at the oil chamber is $40 \mathrm{~mm}$; the diameter of the piston rod at the air chamber is $50 \mathrm{~mm}$; the mass of the pressurized cylinder is set $30 \mathrm{~kg}$; the flow rate of the speed control valve is set 10.787 $\mathrm{L} / \mathrm{min}$ which is a constant; the volume of the hydraulic accumulator is $19.52 \mathrm{~L}$.

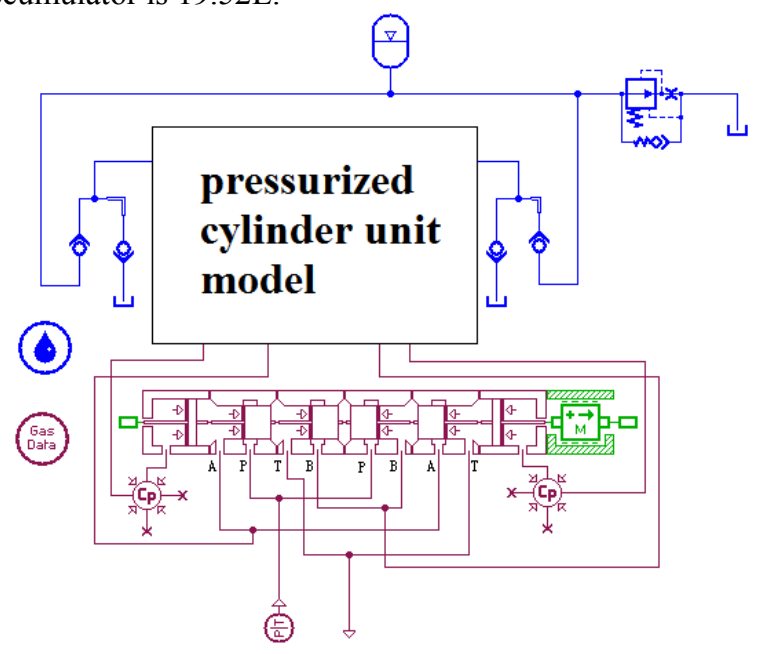

Figure 4. AMESim model of the power source part

Figure 5 shows the displacement and the acceleration of the pressurized cylinder piston. From the figure, we can see that the piston moves back and forward as expected, the stroke of the piston is about $75 \mathrm{~mm}$, the frequency of the piston's movement is approximately $1 \mathrm{~Hz}$. The extreme value of piston acceleration is up to $200 \frac{\mathrm{m}}{\mathrm{s}^{2}}$, but it is acceptable because the inertia force (about $6000 \mathrm{~N}$ ) it causes is relatively low compared to the forces exert on the piston which is about $25000 \mathrm{~N}$.

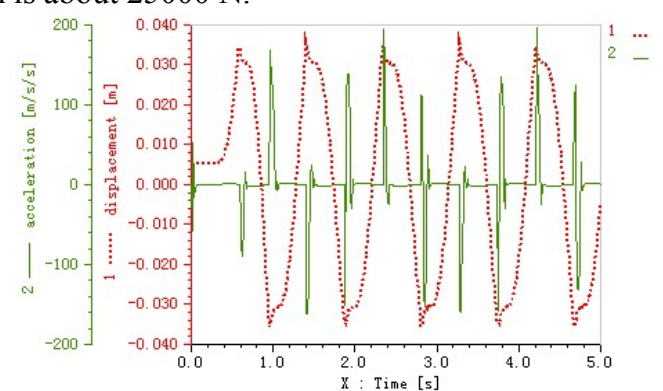

Figure 5. displacement and acceleration of the pressurized cylinder piston

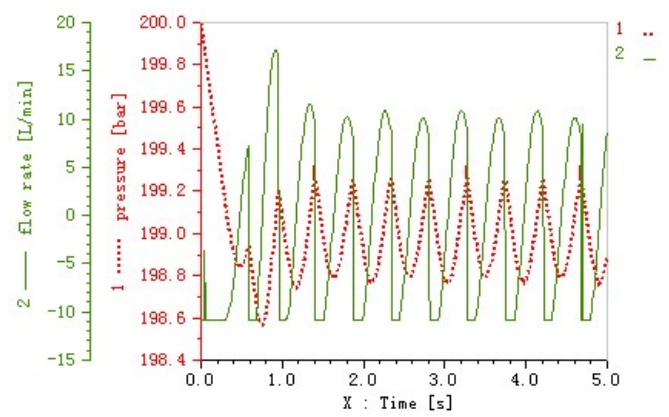

Figure 6. pressure and flow rate of the hydraulic accumulator 
Figure 6 shows the pressure and flow rate of the hydraulic accumulator. Flow rate which is positive means oil flows into the accumulator, and it means oil flows out when it is negative. In the figure, we can see that the pressure in the accumulator varies between 198.8 bar and 199.2 bar, it means the accumulator's pressure is very stable while the system is working.

\section{B. Simulation and result analysis of the function part}

By using the AMESim model of flow divider valve and the models in the "pneumatic" and "hydraulic" libraries, the AMESim model of function part is built, which is show in Figure 7.

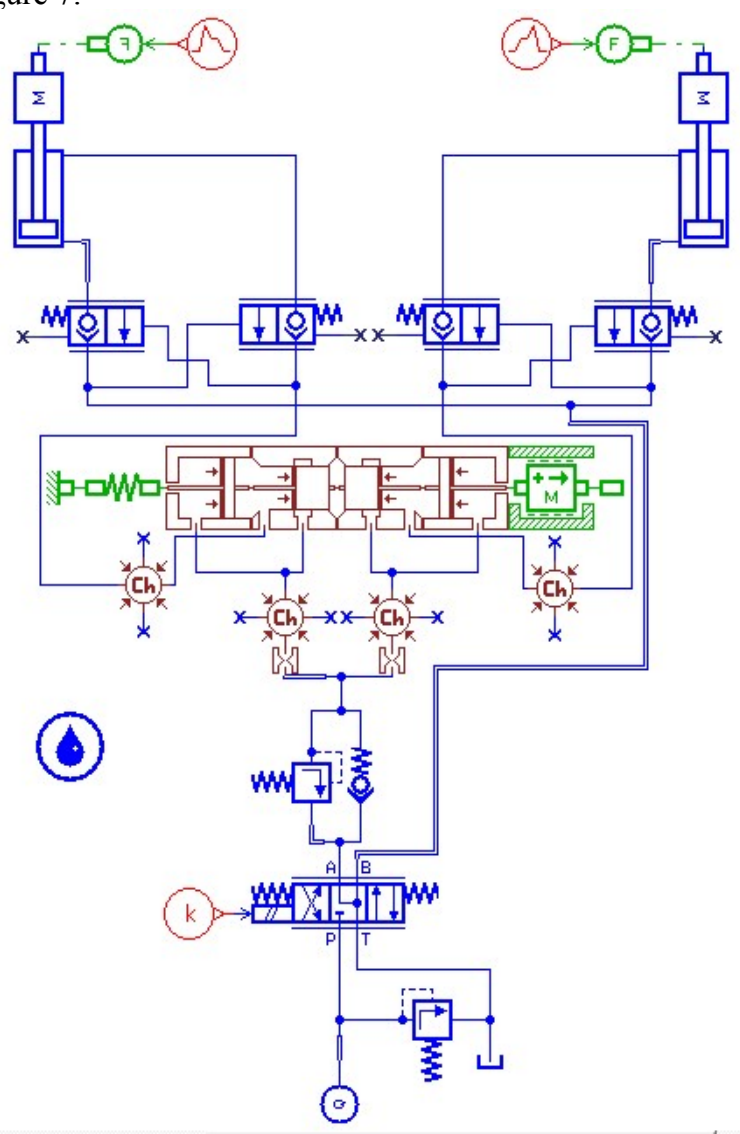

Figure 7. AMESim model of the function part

Firstly, we simulate the working condition when the brake panel is opening, in this working condition the displacement of the hydraulic cylinder piston changes from $200 \mathrm{~mm}$ to 0 while the load exert on the cylinders changes from 0 to $20998 \mathrm{~N}$. When simulating this working condition, the parameters are set as follow: the initial displacement of the hydraulic cylinder piston is set $200 \mathrm{~mm}$; the flow rate of the speed control valve is $10.787 \mathrm{~L} / \mathrm{min}$; the diameter of hydraulic cylinder is $50 \mathrm{~mm}$; the diameter of piston rod is set $28 \mathrm{~mm}$; the mass of piston is set $15 \mathrm{~kg}$.

Figure 8 shows the displacement and the velocity of the hydraulic cylinder piston. In the figure, we can find that the time which the piston takes to finish its stroke is about $3 \mathrm{~s}$, which meets the design request. The piston's velocity when it becomes stable is about $0.05 \mathrm{~m} / \mathrm{s}$, which indicates that the piston is having a constant motion.

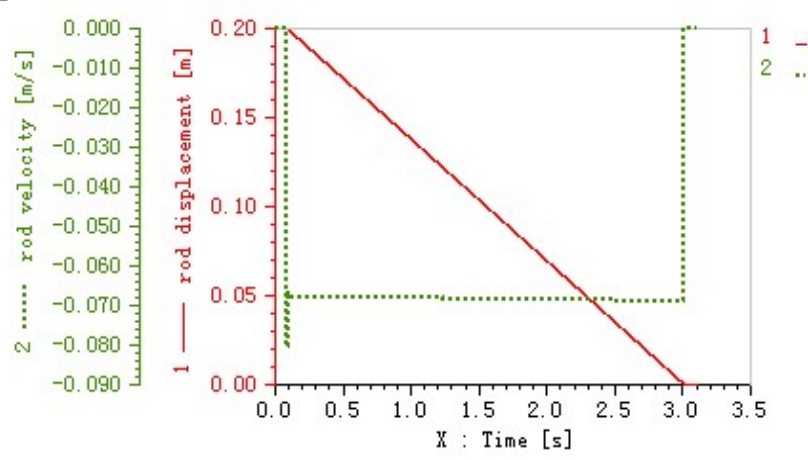

Figure 8. displacement and velocity of hydraulic cylinder piston

Secondly, we simulate the working condition when there is unbalance loading between the two hydraulic cylinders, that is to say when the loads exerting on the two hydraulic cylinders are different. The parameters are the same with those in the brake panel opening working condition. The loads exerting on the left and right hydraulic cylinders are set $20000 \mathrm{~N}$ and $18500 \mathrm{~N}$ separately.

Figure 9 and Figure 10 show rod displacement and flow rate of the two cylinders when there is unbalance load between them. In these two figures, we can find that the left cylinder is about $0.6 \mathrm{~s}$ earlier than the right one when it finish is stroke. And after the left cylinder comes to the end of its stroke, the speed of the right one rises, because after the left cylinder finish its stroke, the pressure will rise to its extreme value. Before the left cylinder finishes its stroke, the difference between the flow rate of the two cylinders is approximately $1.5 \mathrm{~L} / \mathrm{min}$, this is caused by the unbalance load exerting on them. What is worth paying attention to is that although the load on the left cylinder is larger than that of the right one's, the flow rate of the left cylinder is correspondingly larger. This may sound strange, but this result is in compliance with flow rate characteristics of real product of flow divider valves.

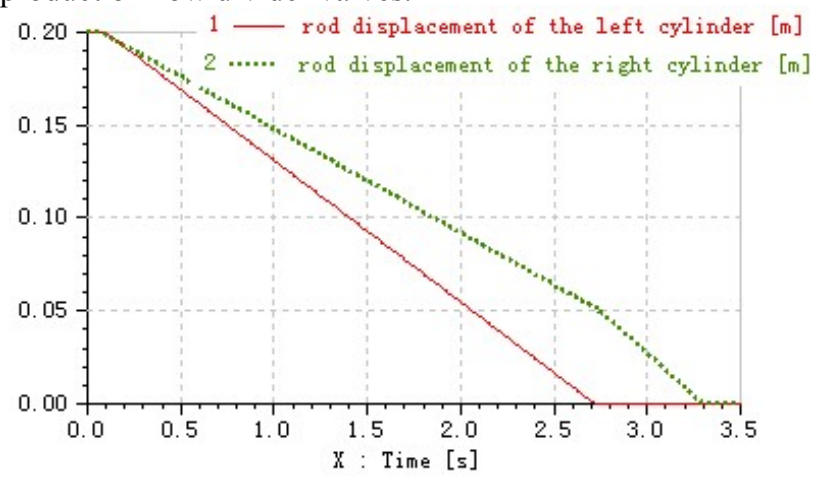

Figure 9. displacement of the two hydraulic cylinders 


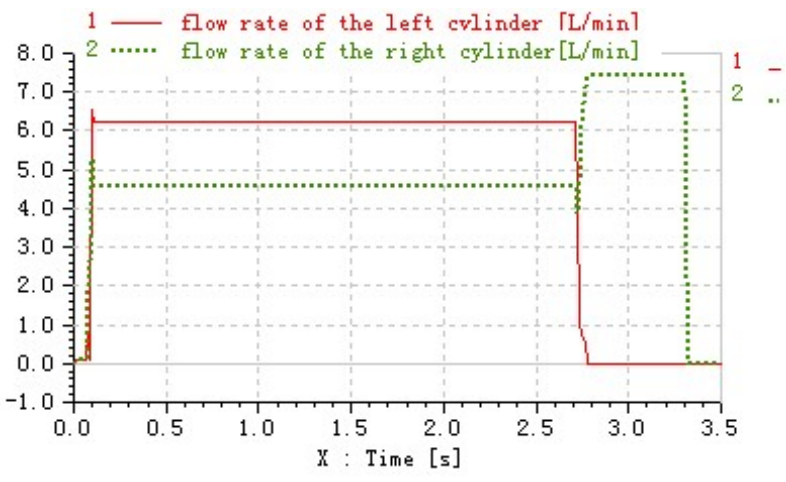

Figure 10. flow rate of the two hydraulic cylinders

\section{CONCLUSIONS}

This paper work uses AMESim software to model the hydraulic system in the aerodynamic brake system. The simulation has been divided into two parts. The performance of the pressurized cylinder has met the design requests though the extreme value of its acceleration is a little high. Under the opening working condition, the hydraulic cylinder can finish its stroke in $3 \mathrm{~s}$, and the flow rate during opening is stable. Under unbalance load working condition, the flow rate and speed of the two hydraulic cylinders are a little different.

\section{ACKNOWLEDGMENT}

This project is supported by National Natural Science Foundation of China (Grant No. 61004077), National Key Technology R\&D Program of the 11th Five year Plan of china(Grant No. 2009BAG11B02), and Foundation of traction power state key laboratory of Southwest Jiaotong University. (Grant No. TPL1107).

\section{REFERENCES}

[1] Chun Tian, Mengling Wu, and Lihui Ren, "Research on aerodynamic brake", Railway Vehicle, vol.27, no.3, pp. 10-12, 2009.

[2] Liping Zhang, "Hydraulic power transmission system and its design", Beijing: Beijing chemical industry press, June 2005.

[3] Liping Zhang, "Hydraulic and Pneuamtic techonology handbook", Beijing: Beijing chemical industry press, December 2006.

[4] Yongling Fu, Kuangye Qi, "AMESim system modeling and simulation", Beijing: Beijing University of Aeronautics And Astronautics Press, June 2006. 